\title{
Working Across Difference: Theory, Practice and Experience
}

\author{
Rachael Dobson ${ }^{1}$ (iD
}

Published online: 3 August 2017

(C) The Author(s) 2017. This article is an open access publication

\begin{abstract}
Back in October 2015 I had the opportunity to chair the book launch for all three works discussed in this review essay. At the event, Shirley Anne Tate said, "Black feminist theory is the theory". The comment referred to how it is not 'just' that Black feminist theory is typically marginalised within institutional contexts and academic scholarship, 'even' within critical, feminist and poststructural work, but also to highlight the capacity of Black feminist scholarship to unpick and destabilise the known and knowable in ways that are profoundly ontological, and which offer potential routes to meaningful social change through the hard task of working across difference. The three books reviewed here by Shirley Anne Tate, Suryia Nayak and Shona Hunter are theoretically rich and complex in breadth, scope and range, drawing on extensive Black feminist scholarship, as well as critical race, critical feminist, psychosocial, psychoanalytic, postcolonial, decolonial and poststructural approaches. Each book is embedded in everyday practices and social processes, offering multi-layered movement across different spatial-social and affective scales in ways that allow 'big' insights to emerge from the locatedness and particularity of human experience. They are reviewed in turn and some concluding comments identify important commonalities across the texts.
\end{abstract}

Keywords Black feminist theory $\cdot$ Practice $\cdot$ Experience $\cdot$ Affect $\cdot$ Power $\cdot$ Politics

Rachael Dobson

r.dobson@kingston.ac.uk

1 Criminology and Sociology, Room 3023, School of Social and Behavioural Sciences, Kingston University, Penryn Road Campus, Kingston Upon Thames, London KT1 2EE, UK 


\section{Tate, Shirley Anne (2015): Black women's bodies and the nation: Race, gender and culture. London. Palgrave}

Shirley Anne Tate's Black women's bodies and the nation: race, gender and culture, is a decolonial theorisation of Black women's agency, specifically their resistance, through an analysis of Black women's bodies and their affects. The book develops a series of powerful and exacting critiques of Black women's representations and positionings in contemporary celebrity and popular culture through sustained intersectional analysis of beauty claims, beauty standards and celebrity status. Tate is explicit about how the book's focus on fat, muscle, bone and skin enables her to deconstruct how claims about 'how Black women's bodies are' come to pass: how they are naturalised and essentialised, and how they are engaged with and resisted by Black women celebrities, their fans and audiences. Taken together, the book builds on Tate's body of scholarship on Black beauty and race performativity (Tate 2005, 2012, 2015, 2016) through its affective and relational critique of Black women's spectacularisation and invisibilisation, the centrality of the white 'Western' gaze to those processes, and how race and gender are thereby central to the constituting of the neo-colonial national project.

A starting point for Tate's intellectual intervention lies in a series of questions that bring together Black women's bodies and nation. Why has the Black woman's body within UK popular culture been located elsewhere, specifically North America (as for Oprah, Michelle Obama, Beyonce), and/or within female celebrities who are called on to 'pass' for North American women because of their positioning within US popular culture (as for Nicki Minaj (Trinidanian) and Rihanna (Barbadian)? How do these women come to speak for 'the' authentic African American woman in the global north? How is it that (trans)national affective entanglements of the Black woman's body are maintained in Europe, the US and Caribbean through a particular (post)colonial racial gender politics (Tate 2015, 6)?

To work through these questions, Tate analyses popular and academic representations of Black women's bottoms (chapter 2 Batty Politics), fat (chapter 3 When Black Fat Does Not Signify Mammy), muscle (chapter 4 Fascination: Muscle, Femininity, Iconicity), slimness (chapter 5 Pleasure Politics: The Cult of Celebrity, Mullaticity and Slimness), skin tone and shade (chapter 6 Skin Lightening) ageing and (dis)ability (chapter 7 Coda). The chapters draw on contemporary Black female icons (Oprah, Michelle Obama), music stars (Beyonce/Sasha Fierce, Nicki Minaj, Lil Kim), sports stars (Serena Williams), music videos (Beyonce and Lady Gaga's Telephone, Lily Allen's Out Here), films (Precious actors Gabourey Sidibe, Monique, Mariah Carey), parody entertainment (Matt Lucas as Precious Little in Little Britain, Big Bertha from Confused.com), stylized and tabloid photographs (Grace Jones, Naomi Campbell), advertising (Alesha Dixon, Thandie Newton, Jessica Ennis, Jeanette Kwakye), celebrity interviews (Mel B), beauty pageant winners (Rachel Christie), and male and female stars from dancehall, soca, calypso, and hip hop cultures (Vybz Kartel, Lisa Hyper).

These examples of Black women in popular and celebrity culture are used to unpick, in detail, the relational and performative dynamics of how Black female 
bodies are (re)created and resisted. Tate's original concept, the Sable Saffron Venus Alter/Native is developed from the outset and called on throughout the chapters to identify Black women's capacities to work against established stereotypes and readings of Black women's representations and actions. Chapter 1 explains the Sable Saffron Venus figure: a monolithic, fixing and disciplining historical reading of Black women's bodies that stuck to the bodies of all Black women in the Caribbean as an effect of affect and (Post)Colonial hygiene: heterosexual white male disgust of, and desiring fear for, Black women's bodies. With this explanation of embodied white racial dominance as a starting point, Tate tracks how 'newness' may enter the world through the agentic and resistant Sable Saffron Venus Alter/ Native that 'sees through' historical, colonial and racist stereotypes of Black women and Black women's bodies.

Importantly, Tate's approach is not simply about revealing agency, resistance and subversion as a straightforward pathway to emancipatory personal change and social transformation via individualising practices of self-love and control over selfrepresentation. Rather, she analyses practices and processes of human agency, theorising a resistant agency that may emerge through excess of skin and body parts. It is "excess and failure in the repetition which allows us to re-cognize the subject as not the stereotype, as agent producing simulacrum" (Tate 2015, 45). The SableSaffron Venus Alter-Native, as the agent producing the simulacrum, refuses the white sexualising and racialising gaze and the Black gaze of respectability that is solely focused on the fetishization of the Black female body-as-object. In these refusals, the Sable-Saffron Venus Alter-Native resists the white sexualising and racialising gaze that denies its own desire to re-make itself through the very skin, muscle, bone and fat of the Black, female racialised other.

Moreover, in conceptualising the power of celebrity within representations of iconic Black women, Tate's Alter/Native stands for an intersectional, disruptive corporeality of class, 'race', gender, age, sexuality and ability (Tate 2015, 164). Black women's capacities to 'be' disruptive and enact social change are theorised using concepts of dis-alienation (Cesaire 2000) and dis-identification (Munoz 1999). These are coupled to theorise the processes associated with potential for social transformation via Black women's agency. Dis-alientation refers here to a performative failure to (re)produce long-established, historical and colonial Black female stereotypes such as for the Hottentot Venus. But dis-alientation can only be effective when twinned with dis-identification, which refers to the ways that structures that exclude Black women and their bodies are disrupted in order that Black women's corporeality-their bottoms, breasts, skin tone, muscle, bone-can become readable on their own terms.

Following this, the significance of the Alter/Native figure is that she emerges as a Black Atlantic (trans)national versioning of female iconicity which is no longer dependent on whiteness to come into being (Tate 2015, 164). To get to this point, Tate exposes the processes through which whiteness (white masculinity, white femininity), its constructions of its racialised psyches, lives and very flesh are constituted via Blackness and Black women's bodies specifically. With whiteness 'put in its place' Tate's analysis illustrates how Black women are able to move beyond historically straitjacketing and subjectifying parody and victimhood towards 
potential for agentic, emancipatory and hopeful futures built from pleasure politics, aesthetic joy and delight, self-love, self-direction, self-creation and self-construction, grounded in Black recognition, production and representation.

Two implications follow. First, Tate's decolonial revisioning of human agency and resistance means that Black women may persist as objects of desire (e.g., as for Naomi Campbell) or parody (e.g., Bertha from Confused.com) in a racist patriarchy. However, there is potential for social change because of how the positioning of subjects provides space for reflection and opportunity within the viewer, and potential for transformation in the representation. In this analysis, conceptions of resistance are also opportunities for subversion in both icon and audience (e.g., viewers, fans of celebrities). This means that both body/gazer and producer can engage in disidentification, via a destabilising of normative ideals on the Black woman's body and resistance to Hottentot assertions in the 21st century (Tate 2015, 65). Second, Tate's detailed analysis of the body itself (muscle, fat, bones, skin), and responses to it (intensified affects like desire, repulsion, disgust and contempt), enables her to identify and unpick how and why certain bodies are deemed 'out of place' (Puwar 2004), and who is then designated as racially other and therefore outside of the nation-the national and social skin-and who is included in the nation albeit on temporary, repressive (contemptuous, intolerant) and always racialised terms (as for 'national child' mixed-'race' Olympic athlete Jessica Ennis, chapter 4 Fascination: Muscle, Femininity, Iconicity).

In developing these arguments Tate works against a series of established critiques and existing debates about Black women and their bodies. In the (re)telling of what agency and resistance looks like the book is explicit about how it challenges common feminist and often white-authored intellectual and popular narratives of Black female celebrities and artists which regard them as exploited replications and reproductions of 19th century Black female figures (such as for Sarah Barttment and the Hottentot Venus). Instead of reading visibility and spectacularisation of fat, bone, skin and muscle as only reproducing oppressive representations and stereotypes, the author argues that Black women's refusals to shield their bodies can be regarded as examples of feminist agency and assertions of individual autonomy and self-representations in everyday life in a context of racialised respectability politics that privileges particular conceptions of morality, intellect and civility. Of course, Tate's point is also that the women she discusses throughout the book are neither Sable-Saffron Venus or Alter/Native: compliant and 'self-hating', 'passive dupes' or excessive and out-of-control (Skin Lightening: Contempt, Hatred, Fear, chapter 6). To stick with that binary, argues Tate, would reproduce an essentialising 'fixing' that attributes certain beauty practices and bodily types as white and 'not Black', or Black in ways that reproduce claims to 'the' authentic Black or white body.

The book also argues against common feminist and often white-authored claims that Black women's bodies can be understood via internalisation of white Eurocentric ideals and norms around beauty and body standards. For Tate, that approach shows how Black Women's diminished agency is often at the service of racist and oppressive structures insofar as it centres whiteness, white women and the white (sexualising, racialising) gaze through the implicit assumption that Black 
woman have as their goal to look and comport as a specific versioning of white women (as youthful, heterosexual and non-disabled) to the disregard of Black histories, locations and contexts. Ultimately the book's critique of the intellectual and popular splitting apart of Black women's body parts (e.g., skin, breasts, bottom, arms) and exposure of the politics of location in the representation and study of Black women's bodies means that we are introduced to how Black women may occupy and break out of 19th century Sable-Saffron Venus tropes, and how the processes associated with these phenomena connect to the performative constituting of 'the West', and of national and transnational border making.

\section{Nayak, Suryia (2015): Race, Gender and the Activism of Black Feminist Theory. London. Routledge}

What is the relationship between racist, homophobic and patriarchal social structures and racist, homophobic and patriarchal psychic structures? To respond to this question, Race, Gender and the Activism of Black Feminist Theory asks what the purpose of binaries and borders are; who and what do they serve as it relates to (essentialising) categorisations and segregations? For example, what are the mechanisms by and through which nouns like Black, white, mixed race, man, woman, transgender, and their placement and positioning effects, come to be? At what point and in what ways does the specificity of a particular social experience become an expression of essentialism? How can differences matter, and the particularity of experience be recognised, in ways that do not work to the benefit of the imperialist and colonising racist, homophobic patriarchy?

Nayak responds to these questions by unravelling how race and gender become mechanisms of oppression. In doing so, she foregrounds the intersecting social and psychic manoeuvres that are constitutive of processes of subject formation. This is a complex task given that a starting point for Nayak is precisely that the colour of skin can mean everything and nothing, at the same time. To work through this complexity, she becomes "host with all of the problematics of being a host" (Nayak 2015,18 ) to an extensive range of theoretical positions and scholars, working across disciplinary boundaries to think about difference, location, voice and the constitutive outside through engagement with positionality, the speech act, author function, representation, interstices, interdependency and borders.

The multiple writings of Audre Lorde (her political essays, journals, poetry, letters, biomythography, speeches and interviews) are central to Nayak's theoretically rich and rigourous analysis of the everyday practices and processes that are in service of oppression. In addition to Lorde, the book draws on critical gender, Black feminist, psychoanalytic and literary theory to both make sense of and identify potential to subvert oppressive practices and structures. At the same time, Nayak is explicit about how her range of experiences as a Black woman existing within the structures of a homophobic, racist patriarchy inform much of the book's substantive orientations: training in social work and psychoanalysis, lecturer in social work, long-standing activism, and campaigning and practice in and for rape crisis centres, asylum seekers and refugee women, and community-based education projects. As 
for Lorde, Nayak fuses the biographical and theoretical and in so doing, works to dismantle the boundaries that are set up between the personal and political as part of opening up possibilities for critical alternative thinkings.

One example of Nayak's sustained examination of structures and borders-their function and production, our fixation on the binary-emerges through focus on Lorde's quotation 'Black feminism is not white feminism in blackface', explored specifically in chapter 3's focus on the question of Black-women-only services and spaces. Bringing in close (re)reading practices and Julia Kristeva's intertextuality as intersubjectivity (wherein the space and place between words function as the (destabilising) space and place between people, ideologies, representation and subjectivities, Nayak understands Lorde's assertion as both acknowledging the psychic life of racism while resisting its terms simultaneously: both positing a knowing of what it means to 'be' Black while troubling it at the very same time. She uses the quotation to unpick how racist, homophobic, patriarchal, subordinating power structures that appear as external get under the skin, into the psyche and go on to constitute Black women's self-identity in a way that is different for white women, white men and Black men.

Drawing on critical postcolonial, race and feminist scholars like Sara Ahmed (1998) and Homi Bhabha (1994), among others, Nayak talks of the differences that matter. That while racism shapes all of our identities and makes us all racist subjects, this operates differently for Black and for white people. In questioning the constructed borders of difference however, Nayak shows that we are not one, nor the other, but something else besides (Bhabha 1994, 28; in Nayak 2015, 16). For the author, that alternative (perhaps as for Shirley Anne Tate's Alter/Native) enables us to question the concept, function and production of borders and boundaries, including the cultural historical context that positions, represents and constitutes Black women as (sister/) outsiders.

Chapter 3 is also significant because of how an engagement with Lorde's assertion that Black feminism is not white feminism in blackface enables Nayak to clarify key principles that are vital to the book's intellectual and political project. These include the relationship between theory, experience and practice (and a critical engagement with each of those terms), the violence of and productive tension associated with borders, and the politics of location that matter for the everyday challenge of survival for Black women existing in the social structures of a homophobic racist patriarchy. Black feminist theory and Lorde's work in particular is understood as being crafted out of the everyday experience of oppression and struggles to be heard, seen and understood.

Following this, Nayak understands theory as a practice of survival: it is processor and container for, response to, articulation and recognition of, the exhaustion, pain and distress of living within the oppressive structures of the racist, homophobic patriarchy. Relatedly, intersectionality is described as a theory which is embedded in the practice of everyday living and survival (The Aporetics of Intersectionality, chapter 4). This is because the experience of surviving in a homophobic, racist and patriarchal society is understood to be an intersectional one, constituted by a range of social actors, institutions and structures, including Black women themselves. Given Nayak's conception of the function of theory for Black women in particular, 
she argues that any attacks on theory-questions about what is it for and why does it matter-represent a refusal to engage with the specific contribution and significance of theory for Black women's and their experiences, and an undermining of the activism of all theory as a vehicle for resistance to oppression in general terms (this particular point is also connected in the concluding chapter to psychoanalytic theory and Wilfred Bion's 'attacks on linking' (Nayak 2015, 120).

Theory is also brought to everyday practice realities associated with efforts to support and provide for Black women. These are "scenes from the drama of everyday practices of imperialism under the lens of the activism of Black feminist theory" (Suryia Nayak, Book launch, 12th October 2015). They are found in responses to questions like "why have separate Black-women only services in a rape crisis centre?' (Black feminism is not white feminism in Black face: the question of Black women only services and spaces, chapter 3) or 'in a short-staffed rape crisis service, should a non-Black and Minority Ethnic (BAME) woman answer the call of a BAME woman on a Black women-only telephone line?' (Conclusion: 'where is the love?', chapter 5). Nayak is explicit in arguing that simplified responses to these questions are dangerous because they mask the very functions and tensions that such questions and answers produce. There is a making-complex-social-phenomenamanageable through the call to binary responses: 'yes' or 'no' (to answering the call), 'present' or 'absent' (who is available or not to answer the call), 'inclusion' or 'exclusion' (who gets to be answered or not). Nayak's intention is to destabilise the binary's features by asking instead:

what do categories of 'Black' and 'white' function to do? Is there a danger here of privileging racial category above service provision? Indeed, is there a danger here of edging very close to the production of the authentic caller and authentic BAME support worker relation? What are the mechanics used in the invocation of the authentic? Does it matter who is speaking? (Foucault 1969). Is the BAME helpline an example of the 'strategic use of positivist essentialism'? (Spivak 2006, 281)? (Nayak 2015, 126)

To be clear, the book is not dismissive of questions about who is provided for and recognised and who is not, whether it be in relation to separate Black women's services, who answers the phone at a rape crisis centre, or a University course reading list. Rather, Nayak's interest is in what is missed when those questions are both posed and responded to. What is the function of the absence and presence and the production of what the binary functions to produce in those instances? What produces the fixations that the question and response is dependent on in the first place? The quotation cited here shows how Nayak is interested to reframe the terms of the question and response in ways that open up, bring in, visibilise and give recognition to processes and practices that would serve to marginalise the oppressive realities that Black women experience, and not just the realities that simplified questions elect to highlight.

While Race, Gender and the Activism of Black Feminist Theory is part of the Routledge critical psychology series, Nayak is clear from the outset that psychology does not feature in the book in ways that might be anticipated by a psychology readership. However, Nayak gives an explicit steer to psychology scholars as to 
what Black feminist scholarship has to offer them, from critical examination of the psy-complex and associated processes of knowledge production that function to establish authenticity, intention, subjectivity and identity, to psychology's failings in how it understands human subjectivity and subject formation. More specifically, Nayak is critical of psychology's conception of how individuals are produced within the contexts that produce them, for example in the idea of subjectivity as constitutive of 'multiple-selves'. These approaches are regarded as efforts to demarcate the subject from structure and demonstrative of a dividing and fragmenting of the self in ways that serve the racist homophobic patriarchy. Such approaches are contrasted with Black feminist scholarship's theories of intersectionality, which offer an everyday performative, affective, relational, temporally and spatially-driven versioning of subjecthood and what it means to be human.

Another way that the book speaks to psychology is through its engagement with what constitutes 'practice'. This emerges through Nayak's engagement with issues of diagnosis and intervention with clients of social workers, psychologists and rape crisis centres. A critical appraisal of intellectual practices is central to the book's contribution: who gets included in as theorist, thinker, valued contributor, and who does not. The notion of practices also relates to the book's articulations of human agency and action, from utterances and talk to documentation and writing. Nayak draws on Butler's (1997) The Psychic Life of Power throughout to think about how all forms of utterances, how they are made possible in the first instance, and how they matter for the creation of Black women's social and psychic reality within any given context. A point sustained throughout the book is that 'things' (the event, the service, the intervention, the identity) are never separated from practices (the decision, the action, the interaction) and their methods (utterances, talk, documentation).

For Nayak, the situation of Black women is a product of practices, which 'we' are always implicated in and cannot stand outside of, and which constitute alwaysunstable social, historical, cultural, economic and political artefacts. As for Shirley Anne Tate's Black women's bodies and the nation: race, gender and culture, these instabilities are potentially agentic insofar as they can give rise to subversion, social transformation and social change but that examining those instabilities, and how and when they do or do not occur, is crucial for understanding Black women's lives and the potential for racial and social justice. The book thereby exposes how examination of scenes from the drama of everyday practices of imperialism highlights what gets suppressed and silenced, and what is made allowable and possible for Black women.

Finally, the relationship between the theory of Black feminist theory and practices is central to Race, Gender and the Activism of Black Feminist Theory's articulation of activism in the everyday. Nayak is clear that activism is the thinking upon which action is contingent. This approach has the effect of focusing attention on the production and function of activism and offers an affective and relational ontology of action as it relates to activism. For example, Nayak argues that practice is intrinsic to Black feminist scholarship such as for Audre Lorde's conception of the erotic. Here, the activism of Black Feminist methodology is understood as an erotic process of feeling (Lorde 1978) in contrast to the Western measure of 
detached validity and reliability. The feeling orientations and dialogical relationship between scholarship, theory, experience and practice produces the methodology of the activism of Black feminist theory, which is always a praxis and a 'doing': a versioning of practice as a praxis that works against borders.

\section{Hunter, Shona (2015): Power, Politics and the Emotions: Impossible Governance? London: Routledge}

Shona Hunter's Power, Politics and the Emotions: Impossible Governance? offers a complex critique of policy process, governance and governing practices to insist upon a hopeful but realistic vision for racial and social justice, founded on ambivalence and unromantic, as opposed to heroic, loss. It is informed by psychosocial, psychoanalysis, critical gender and critical race theory, and poststructuralism, as well as specific theoretical devices such as for psychodynamic theory, melancholia, critical whiteness studies and the psychic life of power. It is difficult to do justice to the book's insights given the depth and range of Hunter's theoretical framework, but it is possible to track some key arguments and contributions.

The book's starting point is governmental failure. Why is it that in spite of efforts to generate social change via mechanisms such as policies on equality and diversity, some people still occupy positions of included/excluded? Why does failure happen in the face of apparently 'positive' aspirations such as for equality? What is the 'pendulum swing' of governmental success and failure about, as hope is invested in administrative change, and then seemingly dashed over time? Responses to these questions examine how failure in governing practices can be rethought of as central to governmental renewal via the study of human experience, agency, subjectivity and emotion.

Loss is central to Hunter's cultural approach to governance. This is because of how loss is potentially generative; necessary and central to human experience and subject forming. Loss means that under certain conditions and in certain contexts the state remains uncertain and potentially open to and for agentic and emancipatory change, albeit that such change needs to be understood in ambivalent and uncertain terms. Power, Politics and the Emotions is committed to demonstrating what these losses are, how they may lead on to change, and the conditions and contexts that both enable and delimit these, through the empirical and theoretical study of governing subjects; welfare workers involved in NHS health practice and professionals delivering equalities training.

The relationships that Hunter draws between the state and human subjectivity are possible because Power, Politics and the Emotions theorises the state as enacted by and through subjects. Drawing on psychoanalysis, psychodynamic theory and unconscious emotion, Hunter's relational, performative and affective critique of what the state is, is fundamental to the book's argument. The state is relational, symbolic, affective and social; it is both material and imagined. Rather than being 'out there', and outside of ourselves, it is constitutive of and through, institutional space (state and civil society, community and family) and human subjects in their 
worlds, and crucially, as enacted through social difference by various subjects and objects, their actions, investments and practices. The state does not exist as a thing in itself (Hunter 2015, 5). This argument rests upon a constant working against any collapse into the binary through a sustained commitment to interdependencies and relationality. It is developed through a series of original concepts such as relational politics, relational choreography, relational hinterland and neoliberal suicide.

Hunter argues that the state comes into being through 'relational politics'; everyday processes of relational contestation and conflict. Hunter explains what these look and sound like, and their effects, through extensive, nuanced and detailed empirical examination of policy documents (chapter 7), governing subjects/welfare professionals (chapters 5 and 6), and at one point, the author's own self-reflexive engagement with these phenomena through involvement in researching and creating equalities documents in an institutional context (chapter 7). The emotions are central to understanding the relationship between human agency, subjectivity and experiences, contestation and conflict, and state enactments, because emotions and power are intimately connected in governance.

For Hunter, the state is typically seen as something that manages emotions as opposed to something that is itself emotional. But emotions work as "connecting devices, bringing together multiple actors and objects into the reasonably temporarily coherent form we think of as the state" (Hunter 2015, 22). Thinking about emotions (e.g., pride, shame) as a type of 'connective medium' enables Hunter to build power into the book's theoretical framework because they are identified as integral to the state's gendered and raced orderings and its enactment of gendered and raced power. Relational politics thinks about the emotions as central to the space 'in-between' the individual and the social order. This is an ethical and negotiating space where politics happens insofar as it is a space where contestations (over social differences) get lived out, managed, resignified and resisted via distribution of emotions, and through relational and intersubjective feeling work.

It is an ethical and political space because of how feeling work coheres subjects and objects, manifesting in refusals to surface multiplicities, and enabling an enactment of the socially and culturally good and bad. This enactment of good and bad works to cover over, to simplify, cohere and make singular the complicated dynamics of conscious/unconscious human subjectivity, positionings and, crucially, the multiplicities that are at play for all of the governing subjects in the book. It works to conceal the social orderings that are the effects of contestation over social difference. This is always an ethical and political set of processes because of how concealments are constituted by, and constituted through, power and inequalities. Thus, one of the key conclusions to the book is the value of keeping this space open as a 'holding' space, and the potential for neoliberal suicide should this space become collapsed through the denial of collective responsibility and desire for (racialised) blame, in ways that connect to intensified emotions and impulses associated with (neo) liberal whiteness, and desires to see the state as a thing outside of ourselves.

In order to develop this argument, Hunter's critical feminist, psychosocial, psychoanalytic (especially dynamic unconscious) and poststructural conceptualisation of human subjectivity is paramount. Human subjectivity is ontological, 
categorical, subjective and relational, constituted through past and present personal histories, biographies, structural tendencies and cultural orderings, and constantly shifting. Human agency is situated through, but not determined by the social relations of power, and takes place relationally through human interactions rather than in any individualised, rationalist and only conscious sense.

Because of this approach to human subjectivity, agency, experience and the emotions, social actors are ambivalently positioned in their social worlds by themselves and institutional and personal/professional others, e.g., past/present organisations, colleagues, clients, family members. These multiplicities mean that human actors may occupy a range of positions at any one time. It is this multiplicity of subject positions and relations that may afford capacities for resistance and social change in a range of places and contexts. Drawing on Gail Lewis's (2000) seminal study of Black women social workers specifically, Hunter demonstrates the capacities that we all have to occupy resistant, dominant and subordinate roles at any one time, as it relates to the various and shifting aspects of our identifications, subjectifications and positionings as enacted by and through institutional space.

As a result, Hunter rejects the potential for resistance to the state and possibilities for social change on the back of straightforward and fixed categorical identifications and/or conscious articulations of resistances to oppressive practices such as for racism and neoliberalism. This is because these approaches privilege conscious action and binary imaginings of social reality and human subjectivity: samenessdifference, for-against, inside-outside the state. Rather, Hunter's empirical examination of governing subjects shows how they are never either 'inside' or 'outside' of the state, co-opted only for or against 'neoliberalising' tendencies, in positions of domination or oppression. Rather, they are multiply positioned within and through the state, negotiating a range of inevitable personal losses, as well as potential gains, via processes of contestation and reconfiguration, which are always ongoing and incomplete.

For Hunter, this grants welfare professionals a "much fuller personhood, more responsibility and innocence than they are often accorded when they are viewed solely, or even primarily as 'agents of the state'” (Hunter 2015, 15-16). It identifies governing subjects as at one and the same time dominant and subordinate, at organisational and personal levels, in different ways and at different times and in different and multiple relations, and it prioritises lived and shifting organisational relations (individual actors' self-perceptions and interactions) alongside other structural and cultural dimensions of social life (the material and cultural categories through which they recognise themselves socially) as well as discursive positionings (Hunter 2015, 27). In Power, Politics and the Emotions governing subjects are engaged in constant negotiations and ongoing (re)configurations, which may in turn constitute resistances under particular conditions and contexts.

For Hunter, the task at hand is to trace these negotiations and reconfigurations as they take place through governance processes and governing practices, from the pulling together of policy documents to the practice realities of welfare work, because it is these negotiations themselves that bring entities like the state into being. Power, Politics and the Emotions is therefore not just a theoretical treatise, it is a methodological argument, which explores the ruptures and interdependencies of 
governing subjects' relational identifications and relational choreographies via detailed empirical analyses. This approach offers a way to understand how agentic social change and resistance are possible even in the most unlikely of people, places and times, but always at the same time, in the same moment, and at the risk of reproducing oppressive practices.

The book's explorations depart from 'mainstream' critiques of the state, governance and policy processes by refusing the sorts of binary and substantialist analyses that are typical of anti-state and anti-neoliberal sentiments and scholarship. While Hunter is sympathetic to aspects of these works, she is also suspicious of representations of governmental practices and governing subjects as coherent and certain, and something already known and knowable. This is because sureties associated with self-proclaimed 'anti' tendencies (anti-state, anti-neoliberalism, anti-racism), and with identifications associated with categorical sameness (even in intersectional analyses), do the work of concealing over and foreclosing the multiplicities, ambivalences and complexities associated with the sorts of human experiences, identifications, subjectivities and positionings that are central to Hunter's understanding of state practices and enactments as having both resistant and oppressive potential.

Moreover, sureties (as found in political decision making and categorical alignments, for example) do the work of hiding how what 'comes to be' is constituted through conceptions of social difference, the struggles and conflicts that these produce and their exclusionary effects, and the ways that power is central to these processes. Hunter understands this power as relating to, and as enacted through, investments in liberal and neo-liberal whiteness, observable through particular mythologies (e.g., fantasies of sameness) and technical instruments and governmentalities (e.g., forms of governing like New Public Management, policy interventions like equalities work).

The 'impossible' component of Hunter's work lies in the series of investments that we all make in different ways in conditions and contexts of power, and the intractable challenges associated with confronting these. Power, Politics and the Emotions is committed to paradox and complexity because for Hunter, the fight for racial justice is only possible through fulsome engagement with ambivalent multiplicities, of taking the time to sit with difference and rest with the intractable entanglements these seem to produce. Attempts to bypass these 'even' by the knowing self-reflexive subject, will always risk reproducing oppressive tendencies and social orderings. However, 'surfacing' the realities of social policy and welfare work that are frequently closed off from intellectual and normative critiques of social policy and welfare are seen by Hunter as crucial for any attempts for a more equal, nourishing and socially just world. This is because they expose the everyday interactions that are a means of organising the lived relations of difference and complexity that are fundamental to state enactments. The book's conclusion is perhaps more hopeful and visionary than the sustained critique of ambivalence and impossibility might suggest. This is achieved through explanation of the potential of uncertainty, of not knowing in a world desirous of knowing and at speed, and the possibilities for social change that may arise from collective responsibility in state formations that are as yet unrealised. 


\section{Conclusion}

The launch for all three books took place in October 2015, and this review essay was written across 2016. As I complete it, the subject of state-making, of nationhood, is both timely and prescient. Taken together, what these books achieve is to take human agency, subjectivity and affects as a starting point for understanding border-making and subject forming, the potential for resistance and subversion and, following Audre Lorde, the very hard work of relating across difference in order to think about the possibilities for racial and social justice in times that may feel closed to change. The books all work, in different ways, to think about how social worlds are dynamically constituted and reproduced without collapsing into individualising analyses. The social subject is always embedded in multiple social relations to objects and entities and multiple selves. Spaces inbetween' are the source of ethics, politics and anti-oppressive possibilities. These are challenging books because of their commitment to destabilising existing debates and ways of knowing. Insights are dense, intense and powerful. They are not always easily understood. But of course a key lesson from these works is that the 'ability' to see, forget, listen and understand-or not-is deeply intertwined with the power/knowledge relation.

Each work ends with personal reflection. Tate describes her mother's illness and treatment, and her agency and resistance, in the face of a social world that is deeply confronted by a Black and disabled older woman. Nayak brings the questions she poses throughout her book to her own life's work and choices. Hunter ponders her own relationship to the state and to practices of hope in the face of loss and failure. On initial reading these books may feel polemical insofar as they offer sustained perspectives and arguments about social reality and human experience. But I want to suggest that these are richly argued, robust and detailed works, driven by the authors' deep engagement with intellectual bodies of scholarship in general and Black feminist scholarship in particular, and with a commitment to scholarship that matters.

Open Access This article is distributed under the terms of the Creative Commons Attribution 4.0 International License (http://creativecommons.org/licenses/by/4.0/), which permits unrestricted use, distribution, and reproduction in any medium, provided you give appropriate credit to the original author(s) and the source, provide a link to the Creative Commons license, and indicate if changes were made.

\section{References}

Ahmed, Sara. 1998. Differences that matter: Feminist theory and postmodernism. Cambridge: Cambridge University Press.

Bhabha, Homi. 1994. The location of culture. London: Routledge.

Butler, Judith. 1997. The psychic life of power: Theories in subjection. Stanford, CA: Stanford University Press.

Cesaire, Aimé. 2000. Discourse on Colonialism. Trans. J. Pinkham. New York: Monthly Review Press. Hunter, Shona. 2015. Power, politics and the emotions: Impossible governance?. London: Routledge.

Lorde, Audre. 1978. Uses of the erotic: The erotic as power. In Sister outsider: Essays and speeches, ed. Audre Lorde, 53-59. Trumansburg, NY: The Crossing Press. 
Munoz, José Esteban. 1999. Disidentifications: Queers of colour and the performance of politics. Minneapolis: University of Minnesota Press.

Nayak, Suryia. 2015. Race, gender and the activism of black feminist theory. London: Routledge.

Puwar, Nirmal. 2004. Space invaders: Race, gender and bodies out of place. Oxford: Berg.

Spivak, Gayatri Chakravorty. 2006. In other worlds: Essays in cultural politics. London: Methuen.

Tate, Shirley Anne. 2005. Black skins, black masks: Hybridity, dialogism, performativity. Abdington: Ashgate.

Tate, Shirley Anne. 2012. Black beauty: Aesthetics, stylization, politics. Abingdon: Ashgate.

Tate, Shirley Anne. 2015. Black women's bodies and the nation: Race, gender and culture. London: Palgrave.

Tate, Shirley. 2016. Skin bleaching in black Atlantic zones: Shade shifters. London: Palgrave. 